\title{
The impact of statins on health services utilization and mortality in older adults discharged from hospital with ischemic heart disease: a cohort study
} Charmaine A Cooke*1, Susan A Kirkland ${ }^{2}$, Ingrid S Sketris ${ }^{2,3}$ and Jafna Cox ${ }^{2,4}$

\author{
Address: ${ }^{1}$ Population Health Research Unit, Dalhousie University, 5790 University Avenue, Halifax, Nova Scotia, B3H 1V7, Canada, ${ }^{2}$ Department \\ of Community Health and Epidemiology, Faculty of Medicine, Dalhousie University, 5849 University Avenue, Halifax, Nova Scotia, B3H 4H7, \\ Canada, ${ }^{3}$ College of Pharmacy, Dalhousie University, 5968 College Street, Halifax, Nova Scotia, B3H 3J5, Canada and ${ }^{4}$ Division of Cardiology, \\ Capital District Health Authority, 2ndFloor, Halifax Infirmary Hospital, 1796 Summer Street, Halifax, Nova Scotia, B3H 3A7, Canada \\ Email: Charmaine A Cooke* - charmaine.cooke@dal.ca; Susan A Kirkland - susan.kirkland@dal.ca; Ingrid S Sketris - ingrid.sketris@dal.ca; \\ Jafna Cox - jafna.cox@dal.ca \\ * Corresponding author
}

Published: 4 November 2009

BMC Health Services Research 2009, 9:198 doi:10.1186/1472-6963-9-198

This article is available from: http://www.biomedcentral.com/1472-6963/9/198

(C) 2009 Cooke et al; licensee BioMed Central Ltd.

This is an Open Access article distributed under the terms of the Creative Commons Attribution License (http://creativecommons.org/licenses/by/2.0), which permits unrestricted use, distribution, and reproduction in any medium, provided the original work is properly cited.
Received: 3 December 2008

Accepted: 4 November 2009

\begin{abstract}
Background: Cardiovascular disease (CVD) carries a high burden of morbidity and mortality and is associated with significant utilization of health care resources, especially in the elderly. Numerous randomized trials have established the efficacy of cholesterol reduction with statin medications in decreasing mortality in high-risk populations. However, it is not known what the effect of the utilization of these medications in complex older adults has had on mortality and on the utilization of health services, such as physician visits, hospitalizations or cardiovascular procedures.
\end{abstract}

Methods: This project linked clinical and hospital data from the Improving Cardiovascular Outcomes in Nova Scotia (ICONS) database with administrative data from the Population Health Research Unit to identify all older adults hospitalized with ischemic heart disease between October 15, 1997 and March 3I, 200I. All patients were followed for at least one year or until death. Multiple regression techniques, including Cox proportional hazards models and generalized linear models were employed to compare health services utilization and mortality for statin users and non-statin users.

Results: Of 4232 older adults discharged alive from the hospital, I 629 (38\%) received a statin after discharge. In multivariate models after adjustment for demographic and clinical characteristics, and propensity score, statins were associated with a $26 \%$ reduction in all- cause mortality (hazard ratio (HR) $0.74,95 \%$ confidence interval $(\mathrm{Cl}) 0.63-0.88)$. However, statin use was not associated with subsequent reductions in health service utilization, including re-hospitalizations $(\mathrm{HR}, 0.98,95 \% \mathrm{Cl}$ 0.91 - I.06), physician visits (relative risk (RR) $0.97,95 \% \mathrm{Cl} 0.92-\mathrm{I} .02$ ) or coronary revascularization procedures (HR I.15, 95\% Cl 0.97-I.36).

Conclusion: As the utilization of statins continues to grow, their impact on the health care system will continue to be important. Future studies are needed to continue to ensure that those who would realize significant benefit from the medication receive it. 


\section{Background}

Although mortality from cardiovascular disease (CVD) has been decreasing steadily in Canada, it is still the leading cause of death, accounting for $33 \%$ of all mortality in 2003 [1-3]. Patients with CVD have a high burden of morbidity and utilize significant health care resources, resulting in high health care costs. In 1998, CVD represented the most costly diagnostic category, accounting for a total cost of $\$ 18.5$ billion in Canada (11.6\% of total costs of all illnesses) $[3,4]$.

In several randomized controlled trials (RCTs) [5-12], the use of statins has been shown to substantially reduce the occurrence of morbidity and mortality in people with coronary artery disease. Consistent treatment effects across multiple groups, including older adults [13-17] have been demonstrated. The evidence on the efficacy of statins from these RCTs has led to widespread use of these medications in all age groups [18-20].

Gaps in evidence may exist on the safety and effectiveness of drugs during real world use where drugs may be often used by diverse patient groups outside the controlled environment of clinical trials [21-23]. In particular, older adults who may have many concomitant diseases, complex drug regimens and cognitive and functional decline are often excluded from RCTs; this may limit the generalizability of RCTs to these populations. Therefore, the impact of statins on mortality and health service utilization in the real world in older adults may need to be explored.

The purpose of this study was to determine if older adults who received statins after discharge from hospital would have better health outcomes (less use of health services and decreased mortality) compared to those who did not receive statins.

\section{Methods}

\section{Data Sources}

The Improving Cardiovascular Outcomes in Nova Scotians (ICONS) project was a multi-stakeholder, provincewide initiative that first enrolled patients on October 15, 1997 [24]. It includes a registry of all patients in Nova Scotia, Canada hospitalized with a diagnosis of ischemic heart disease (IHD), congestive heart failure or atrial fibrillation [25]. Data for the ICONS study was retrospectively abstracted from patient charts; variables include patient demographics, laboratory and diagnostic tests, social history, cardiovascular risk factors, medical history, in-hospital cardiovascular procedures and admission and discharge medications.

The Population Health Research Unit (PHRU), Dalhousie University, houses population-level administrative health data for the province of Nova Scotia [26]. The data repository contains comprehensive information about insured health services delivered to residents of Nova Scotia from 1989 onward. The databases at PHRU contain information on vital statistics, physician billings, hospitalizations and all prescriptions dispensed to eligible adults 65 years and over registered in the Nova Scotia Pharmacare Program.

\section{Study Cohort and Design}

A retrospective cohort design was used. The study population included all individuals $\geq 66$ years old registered in the Nova Scotia Seniors Pharmacare Program (NSSPP) who were discharged alive from hospital in Nova Scotia, Canada between October 15, 1997 and March 31, 2001, with a diagnosis of IHD. The NSSPP is a publicly funded drug insurance plan that reimburses drugs and medical supplies listed in the Nova Scotia Formulary for entitled seniors in the province. The beneficiaries of this program are seniors with a minimum age of 65 years who enrolled in the program by paying the required insurance premium and the co-payments. The NSSPP does not provide coverage for senior residents who have private drug insurance, benefit coverage with Veterans Affairs Canada or First Nations and Inuit Health. Approximately $85 \%$ of seniors in Nova Scotia are eligible beneficiaries under the NSSPP; the remainder of the senior population has drug coverage under private or Federal programs (Data on file, Population Health Research Unit, Dalhousie University). Patients were followed for at least one year or until death; if a patient had more than one hospital admission during the study period, the first hospitalization date was used as the index hospitalization. This study received approval from the Research Ethics Board of the Capital Health District Health Authority, Halifax, Nova Scotia.

\section{Measures of Outcomes and Exposures}

The primary outcome of interest was defined as the utilization of health services (physician services, hospitalizations, or a coronary revascularization procedure) after the index discharge from hospital with IHD, and within the follow-up period (to March 31, 2002 or death). The secondary outcome measure was all-cause mortality after the index hospitalization.

The primary exposure of interest was the dispensing of at least one prescription for a statin medication after discharge from hospital as identified through the Nova Scotia Pharmacare databases. Non-initiators of statin medications were defined as those patients receiving no statin prescriptions for at least one year before hospital admission and throughout the study period. New initiators of statin medications were defined as those patients who received at least one prescription for a statin after hospital discharge. Statins were identified using Drug 
Identification Numbers (DINs), a Canadian system used to identify unique drug products and through the Anatomical Therapeutic Chemical (ATC) classification system $[27,28]$.

\section{Statistical Analysis}

Descriptive Analysis

Descriptive statistics were used to compare baseline patient characteristics between groups using chi-squared tests for categorical variables and Student t-tests for continuous variables. Bivariate associations were examined with Mantel Haenszel summary odds ratios to determine possible interactions or effect modification between statin therapy, mortality and age or gender. No age or gender interactions were identified.

The number of distinct medications prescribed in the previous year (NODMP) is one method used to adjust for comorbidity in administrative database studies [29-36]. As the NODMP is easy to access and calculate and has been validated [33,35,37-39], and as health service utilization was the primary outcome measure for this project, the NODMP was used as the method to adjust for co-morbidity.

\section{Propensity Model}

In observational studies, there is no control over treatment and the exposed and unexposed groups may have large differences in their observed covariates, which lead to biased estimates of treatment effects [40,41]. Propensity analysis attempts to identify patients who are similar except for their treatment assignment to approximate the conditions of a randomized controlled trial [40-44].

A multivariate logistic regression model was generated to estimate for each patient the propensity to receive a statin after discharge from hospital. Available clinical, demographic and treatment variables were incorporated into the model. The variables included in the propensity score model are listed in Table 1 . The ability of the model to dis-

Table I: List of Variables entered into the Propensity Model and their Description

\begin{tabular}{|c|c|c|}
\hline Variable & Measure & Source \\
\hline \multicolumn{3}{|l|}{ Outcomes and Exposures } \\
\hline Physician Visits & Continuous & PHRU physician services database \\
\hline Hospitalizations & Continuous & PHRU hospitalization database \\
\hline Coronary Re-vascularizaton & Continuous & ICONS (Inpatient chart) \\
\hline Mortality & Yes/No & ICONS (Vital Statistics) \\
\hline \multicolumn{3}{|l|}{ Demographics } \\
\hline Age & $\begin{array}{l}\text { Continuous } \\
\text { Categorical: } 66-75,75-80,>80 \text { (by tertiles) }\end{array}$ & PHRU (Pharmacare database) \\
\hline Gender & Male, Female & ICONS (Inpatient chart) \\
\hline Region of Province where Patient Resides & Northern, Eastern, Western, Southern & ICONS (Inpatient chart) \\
\hline \multicolumn{3}{|l|}{ Risk Factors } \\
\hline Total blood cholesterol measured in hospital & Yes/No & ICONS (Inpatient chart) \\
\hline LDL cholesterol measured in hospital & Yes/No & ICONS (Inpatient chart) \\
\hline HDL cholesterol measured in hospital & Yes/No & ICONS (Inpatient chart) \\
\hline Triglycerides measured in hospital & Yes/No & ICONS (Inpatient chart) \\
\hline Diabetes & Yes/No & ICONS (Patient reported) \\
\hline Hypertension & Yes/No & ICONS (Patient reported) \\
\hline Smoking & Past, Current, Never & ICONS (Patient reported) \\
\hline Family History of CVD & Yes/No & ICONS (Patient reported) \\
\hline Previous PTCA & Yes/No & ICONS (Patient reported) \\
\hline Previous CABG & Yes/No & ICONS (Patient reported) \\
\hline Previous CHF & Yes/No & ICONS (Patient reported) \\
\hline Previous Cardiac Catheterization & Yes/No & ICONS (Patient reported) \\
\hline Previous Myocardial Infarction & Yes/No & ICONS (Patient reported) \\
\hline Previous stroke & Yes/No & ICONS (Patient reported) \\
\hline Previous TIA & Yes/No & ICONS (Patient reported) \\
\hline Year of Entry into study & By Quartiles & ICONS (Inpatient chart) \\
\hline $\begin{array}{l}\text { Number of distinct prescription medications in } 6 \text { months pre- } \\
\text { hospitalization }\end{array}$ & $\begin{array}{l}\text { Continuous } \\
\text { Categorical: }<3,3-<6,6-<9, \exists 9 \text { (by quartiles) }\end{array}$ & PHRU Pharmacare database \\
\hline \multicolumn{3}{|l|}{ In-hospital clinical data } \\
\hline Discharge diagnosis & UA/AMI & ICONS (Health Records) \\
\hline $\begin{array}{l}\text { In-hospital procedures } \\
\text { (PTCA, CABG, EST, Cardiac catheterization) }\end{array}$ & Yes/No & ICONS (Inpatient Chart) \\
\hline $\begin{array}{l}\text { Medications on discharge } \\
\text { (ASA, Beta-blockers, CCB, ACE, Fibrates) }\end{array}$ & Yes/No & ICONS (Inpatient Chart) \\
\hline
\end{tabular}


criminate between patients who did and did not receive statin therapy was assessed with the c-statistic. The study population was divided into quintiles of increasing probability for statin initiation, and the propensity score was entered by quintile level into the final multivariate regression models used to determine the relationship between statins and the outcomes of interest [41-44].

\section{Multivariate Analysis}

Once propensity scores had been estimated for each patient, the scores were sorted in ascending order, and then stratified into quintiles. Propensity scores by quintiles were fairly well matched between statin initiators and non-initiators. As the goal of stratification is to remove differences in covariates between the two groups, covariates were examined within each quintile for statin initiators and non-initiators to ensure that the two groups were well matched for each covariate; any variables that were not balanced within a quintile were included in the final multivariate models as first order interaction terms. Other variables forced into the final multivariate models included age and gender.

We determined the impact of the number and rate of rehospitalizations using generalized linear models (GLM) and Cox proportional hazards models. GLM was also used to examine the relationship between statins and the number of physician services per person. The negative binomial distribution was used in the GLM models as the Poisson assumption was violated. Cox proportional hazards models were used to estimate the HR and 95\% CI for the association between coronary revascularizations statins and mortality and statins. All multivariate analyses were undertaken both with and without propensity adjustment.

All statistical analysis was undertaken using the SAS statistical computer program version 8.2 [45] and models were developed using a non-automated, backwards selection process.

\section{Results \\ Baseline Characteristics}

The study population consisted of 4232 older adults discharged alive from the hospital with a diagnosis of IHD between October 15, 1997 and March 31, 2001. The mean age was 77.5 years $( \pm 7$ years $)$, and $48 \%(\mathrm{n}=2036)$ were male. A total of $38 \%$ of patients $(n=1629)$ were dispensed a statin during the study period. Overall, patients were followed for an average of $28.0( \pm 14.6$ months) months from discharge, during which time $26 \%$ of patients $(\mathrm{n}=1120)$ died. The percentage of those receiving statins remained relatively stable over the study period, with annual rates of utilization of $39.1 \%, 38.8 \%$, $37.7 \%$ and $38.4 \%(\mathrm{p}=0.92)$. Over $50 \%(52.7 \%)$ of patients received their first statin prescription within 30 days of hospital discharge, $19.5 \%$ of patients received their first prescription for a statin within 90 days of discharge, $17.4 \%$ within 365 days, and $10.4 \%$ received the first statin prescription 365 days after discharge.

The demographic and clinical characteristics of the 4232 patients in the cohort are described in Table 2 . There were notable differences between statin initiators and non-initiators. On index hospital admission, statin initiators seemed healthier in that they were younger, less often had a history of a CVD, and had fewer prescription medications dispensed in the six months pre-hospitalization. However, they were more likely to be current smokers and to have a family history for CVD. During the index hospitalization, statin initiators more often received a coronary revascularization procedure, and were more often prescribed cardiovascular medications on discharge. The cstatistic for the propensity model was 0.78 , indicating that the propensity model discriminated acceptably between patients receiving a statin on discharge and those who did not [44]. A model with a c-statistic of 0.5 would reflect a completely random prediction model, while a model that discriminates perfectly between patients with and without an event would have a c-statistic of 1.0.

\section{Impact of Statins on Health Services Utilization}

Although the percentage of older adults re-admitted to the hospital for any cause was decreased by $16 \%$ (HR 0.84 , 95\% CI 0.78-0.90) before propensity adjustment, this beneficial effect disappeared once propensity scores were incorporated into the model (Table 3). Adjusting for propensity score resulted in a similar trend for the impact of statins on the percent of those with CVD-related re-hospitalizations. Before propensity adjustment, statins had no impact on CVD-related re-hospitalization rates in older adults; however, after propensity adjustment there was an $11 \%$ increase those with CVD-related re-hospitalizations (HR 1.11, 95\% CI 1.02-1.22). The number of all-cause rehospitalizations and CVD-related re-hospitalizations per senior was not affected by statins use either before or after propensity adjustment (Table 3 ).

Although statins decreased the number of physician visits in older adults by $16 \%$ before propensity adjustment (RR $0.84,95 \%$ CI $0.79-0.88$ ), this beneficial effect was also removed after adjustment for propensity in the model. Statin use was associated with an $18 \%$ increase in the number of CVD-related physician visits (95\% CI 1.091.29 ) before propensity adjustment and a $34 \%$ increase (95\% CI 1.23-1.46) after propensity adjustment (Table 3).

Coronary revascularization procedures were significantly increased in those receiving statins before propensity adjustment (HR 1.55, 95\% CI 1.30-1.84). However, in 
Table 2: Characteristics of $\mathbf{4 2 3 2}$ Nova Scotia seniors discharged from hospital with unstable angina or myocardial infarction

\begin{tabular}{|c|c|c|c|}
\hline Characteristic & Statin Dispensed $(n=1629)$ & No Statin Dispensed $(n=2603)$ & $p$ value \\
\hline \multicolumn{4}{|l|}{ Demographics } \\
\hline Age (years) (range) & $74.6 \pm 5.7$ (66-98 years) & $79.2 \pm 7.1$ (66-101 years) & $<0.0001$ \\
\hline Gender (Males) & $49.8 \%$ & $47.1 \%$ & 0.085 \\
\hline \multicolumn{4}{|l|}{ Risk Factors/Comorbidities } \\
\hline Hypertension & $58.8 \%$ & $58.2 \%$ & 0.705 \\
\hline Smoking & & & $<0.0001$ \\
\hline Never & $48.9 \%$ & $57.9 \%$ & \\
\hline Current & $18.00 \%$ & $13.5 \%$ & \\
\hline Past & $33.1 \%$ & $28.6 \%$ & \\
\hline Family history of CVD & $15.3 \%$ & $8.4 \%$ & $<0.0001$ \\
\hline Diabetes & $26.2 \%$ & $29.0 \%$ & 0.047 \\
\hline History of CHF & $8.5 \%$ & $17.6 \%$ & $<0.0001$ \\
\hline History of MI & $25.8 \%$ & $30.9 \%$ & 0.0004 \\
\hline History of Stroke & $6.4 \%$ & $11.5 \%$ & $<0.0001$ \\
\hline History of TIA & $4.5 \%$ & $7.5 \%$ & $<0.0001$ \\
\hline $\begin{array}{l}\text { Number of distinct prescription medications in } 6 \text { months pre- } \\
\text { hospitalization }\end{array}$ & $5.7 \pm 4.2$ & $6.6 \pm 4.6$ & $<0.0001$ \\
\hline Area in Province Patient Resides & & & 0.035 \\
\hline North & $18.1 \%$ & $17.6 \%$ & \\
\hline Central & $35.1 \%$ & $32.5 \%$ & \\
\hline East & $21.7 \%$ & $20.8 \%$ & \\
\hline West & $25.0 \%$ & $29.0 \%$ & \\
\hline \multicolumn{4}{|l|}{ Factors During Index Hospitalization } \\
\hline \multicolumn{4}{|l|}{ Discharge Diagnosis } \\
\hline Unstable Angina & $46.0 \%$ & $51.0 \%$ & 0.001 \\
\hline Myocardial Infarction & $54.0 \%$ & $49.0 \%$ & \\
\hline \multicolumn{4}{|l|}{ In-hospital procedures } \\
\hline CABG & $6.0 \%$ & $3.7 \%$ & 0.0004 \\
\hline Cardiac catheterization & $27.1 \%$ & $15.6 \%$ & $<0.0001$ \\
\hline PTCA & $10.8 \%$ & $5.7 \%$ & $<0.0001$ \\
\hline EST & $48.8 \%$ & $25.1 \%$ & $<0.0001$ \\
\hline \multicolumn{4}{|l|}{ Concomitant medications written at hospital discharge } \\
\hline ASA & $85.2 \%$ & $75.3 \%$ & $<0.0001$ \\
\hline ACE inhibitor & $46.2 \%$ & $47.6 \%$ & 0.375 \\
\hline Beta-blocker & $83.1 \%$ & $75.9 \%$ & $<0.0001$ \\
\hline Calcium channel blocker & $37.4 \%$ & $37.5 \%$ & 0.950 \\
\hline Fibrates & $6.1 \%$ & $4.9 \%$ & 0.0092 \\
\hline \multicolumn{4}{|l|}{ Cholesterol Levels measured in Hospital (Y/N) } \\
\hline Total cholesterol & $68.1 \%$ & $46.0 \%$ & $<0.0001$ \\
\hline LDL cholesterol & $63.1 \%$ & $42.0 \%$ & $<0.0001$ \\
\hline HDL cholesterol & $50.9 \%$ & $49.1 \%$ & $<0.0001$ \\
\hline Triglycerides & $54.5 \%$ & $45.5 \%$ & $<0.0001$ \\
\hline \multicolumn{4}{|l|}{ Factors Post-Index Hospitalization } \\
\hline Follow-up (\# years) & $2.7 \pm 1.1$ & $2.1 \pm 1.2$ & $<0.0001$ \\
\hline Crude Mortality & $11.4 \%$ & $35.9 \%$ & $<0.0001$ \\
\hline
\end{tabular}

contrast to the other outcome measures, including the propensity in the model negated this increase (Table 3 ).

\section{Impact of Statins on Mortality}

After adjustment for clinical and demographic variables, patients who received statins had a 59\% reduction in mortality compared with patients who did not receive statins (HR 0.41, 95\% CI 0.35-0.49). After the propensity score was incorporated into the model, statins were associated with a $26 \%$ reduction in mortality (HR $0.74,95 \%$ CI 0.63 0.88) (Table 3).

\section{Discussion}

This study found that older adults receiving a statin after discharge from hospital with IHD realized significant mortality benefits; however, reductions in re-hospitalizations, physician visits, or coronary revascularizations were not demonstrated over the follow-up period of approximately two years.

Thirty-eight percent (38\%) of older adults discharged from hospital received statins in our study; this may seem inconsistent with current North American guidelines 
Table 3: Hazards ratios and relative risks for the association between statins and health service utilization/mortality in 4232 Nova Scotia seniors discharged from hospital with unstable angina or myocardial infarction

\begin{tabular}{|c|c|c|}
\hline Outcome & $\begin{array}{l}\text { Impact of Statins on rate of events modeled } \\
\text { using Cox Proportional Hazards (HR, 95\% Cl) } \\
\text { (Statin versus No Statin) }\end{array}$ & $\begin{array}{l}\text { Impact of Statins on number of events, } \\
\text { modeled using Generalized Linear Models (RR, } \\
95 \% \mathrm{CI}) \text { (Statin versus No Statin) }\end{array}$ \\
\hline \multicolumn{3}{|l|}{ All-cause re-hospitalizations } \\
\hline Modeled without propensity score & $0.84(0.78-0.90)$ & $0.97(0.90-1.04)$ \\
\hline Modeled with propensity score & $0.98(0.91-1.06)$ & $1.04(0.97-1.12)$ \\
\hline \multicolumn{3}{|l|}{ CVD re-hospitalizations } \\
\hline Modeled without propensity score & $0.98(0.90-1.07)$ & $0.90(0.86-1.12)$ \\
\hline Modeled with propensity score & $1.11(1.02-1.22)$ & $1.03(0.92-1.16)$ \\
\hline All physician visits & $N / A$ & \\
\hline Modeled without propensity score & & $0.84(0.79-0.88)$ \\
\hline Modeled with propensity score & & $0.97(0.92-1.02)$ \\
\hline CVD-related physician visits & $N / A$ & \\
\hline Modeled without propensity score & & $1.18(1.09-1.29)$ \\
\hline Modeled with propensity score & & $1.34(1.23-1.46)$ \\
\hline Coronary Revascularizations & & N/A \\
\hline Modeled without propensity score & $1.55(1.30-1.84)$ & \\
\hline Modeled with propensity score & $1.15(0.97-1.36)$ & \\
\hline Mortality & & $\mathrm{N} / \mathrm{A}$ \\
\hline Modeled without propensity score & $0.41(0.35-0.49)$ & \\
\hline Modeled with propensity score & $0.74(0.63-0.88)$ & \\
\hline
\end{tabular}

which suggest that most patients at high-risk for CVD disease should receive treatment with these medications regardless of age $[46,47]$. The low utilization of statins in our population may be a reflection of the study period (1997-2001), with other studies reporting utilization of statins in older adults with established disease over this time period describing similar prescribing rates [48-51].

This study demonstrated that older adults with increased markers for disease severity were less likely to be dispensed statins after discharge than were their healthier counterparts. Other published studies have also shown consistent treatment biases for the use of statins in the older adults at highest risk for developing CVD $[37,39,48,49,52,53]$. Although some published studies have reported that females with CVD were treated less often than their male counterparts [18,54-57], our results agree with more recent reports that do not demonstrate this treatment bias $[48,58-60]$.

While there is limited data describing health service utilization associated with statin use, we were somewhat surprised that we did not observe a decrease in health service utilization associated with statins similar to that seen in randomized trials [61-63]. Many authors have postulated various mechanisms, including plaque stabilization and improved endothelial function [64-69] that would support the benefits of statin therapy on a variety of health outcomes, including CVD-related events and coronary revascularizations. However, our results are similar to those demonstrated in two other observational studies that examined the impact of statins on re-hospitalizations
[38,70], Perhaps more aggressive management of CVD, reflected by prescribing of statins, results in regular ongoing patient follow-up and management, leading to increases in health services utilization.

There may be other reasons why older adults access health services that may have little to do with ill health or with medication utilization. A vast array of health service utilization influences have been identified including societal factors, availability of physicians and hospital beds, and personal factors $[71,72]$. Many of these factors may have impacted physician visits, re-hospitalizations and coronary revascularization procedures to a greater degree than the use of statin medications in a real-world population.

While statin therapy was associated with increases in CVD-related re-hospitalizations and CVD-related physician visits, these increases may be correlated. Older adults receiving statins may visit their physician for a CVDrelated cause more often than those not receiving statins due to ongoing lipid monitoring or to receive a new statin prescription. Due to these increases in physicians' visits, there could be a "detection bias" in that patients that visit their physician may be more likely to be investigated more aggressively for chest pain and be referred to the hospital for recurrent angina.

After adjustment for clinical and demographic variables, statins were associated with a $26 \%$ reduction in mortality (HR 0.74, 95\% CI 0.63-0.88) after propensity adjustment. The $26 \%$ reduction in mortality associated with statin therapy in older adults with CVD in our study is similar to 
results demonstrated in two large randomized trials [61$63]$ and in two meta-analyses $[73,74]$ of trials in older adults taking statins.

There have been few observational studies examining the effect of statins on all-cause mortality in older adults with CVD. One recent observational study of 2626 patients 65 years and older with established CVD living in nursing homes [70] demonstrated a 31\% reduction in one-year mortality associated with statins. Nonetheless, as older adults admitted to nursing homes often have a high acuity of illness, it is difficult to determine if the benefits demonstrated could be extrapolated to a community dwelling senior population.

Three other studies [75-77] examined the use of statins in patients discharged from hospital with CHD, with stratification by age to determine mortality in older adults. While significant reductions in mortality were demonstrated (28\%-60\%), these studies did not incorporate propensity analysis techniques into their analysis. One other published study has examined the impact of statins on mortality in older adults discharged from hospital with an AMI that incorporated propensity analysis techniques into the analysis [78]. The authors demonstrated that discharge statin therapy was associated with a decrease in 3year mortality similar to that found in our study (HR 0.89, 95\% CI 0.83-0.96). However, mortality reductions were not evident in those aged 80 years and older. While this age-statin interaction was not demonstrated in our study, this issue needs further exploration.

Several limitations of our study merit consideration. First, statin therapy was not randomly assigned, introducing an important source of bias into the study. Despite adjustments for confounding through multivariate techniques incorporating covariates and propensity adjustment, residual confounding from unobserved or unmeasured confounders cannot be excluded.

Although Canada has a universal health insurance system, access to hospital services, physician services and cardiac procedures has shown to vary with socioeconomic status and across regions [79-81]. While all older adults in this study had coverage for prescription medications through the Nova Scotia Pharmacare Program, prescription copayments did increase over this study period, from $20 \%$ to $33 \%$ of each prescription. This may have affected medication access over the study period, although one recent Canadian study disputes this theory [81]. As this study examined older adults discharged from the hospital with IHD, the results may not be generalizable to older adults recruited from primary care. Finally, data was not available on compliance with or discontinuation of statins during the study period. An analysis of these factors may reveal important differences in outcomes depending on the length of time that a person receives the medication. Nonetheless, as our study examines the impact of statin use on health services use and mortality in all statin users, our outcomes reflect those that occur in real-world use of these medications.

\section{Conclusion}

Based on the results of this population-based observational study, we conclude that statins are associated with important reductions in mortality in older adults discharged from hospital with cardiovascular disease. Rehospitalizations and physician visits were not decreased by statin utilization, however, the number of CVD-related physician visits per senior, and the rate of CVD-related rehospitalizations were increased, a finding which requires further exploration.

As the utilization of statins continues to grow, their impact on the health care system will continue to be important. Future studies are needed to continue to determine which patients should receive statins, the optimal time from diagnosis to initiation, and strategies to ensure that those who would receive significant benefit from these medications receive it. Further exploration of the relationship between statin use and health services use is required in order to promote safe, appropriate and costeffective management of older adults with CVD.

\section{Competing interests}

The authors declare that they have no competing interests.

\section{Authors' contributions}

$\mathrm{CC}$, SK, IS and JC made substantial contributions to the design and interpretation of the study. CC performed the statistical analysis. CC and SK drafted the manuscript. All authors read and approved the final manuscript.

\section{Acknowledgements}

Funding for data provided by the Population Health Research Unit was provided by the College of Pharmacy, Dalhousie University, Halifax, Nova Scotia, Canada, through the Pharmacy Endowment Fund. Charmaine Cooke was partially supported by a studentship from the Nova Scotia Health Research Foundation.

\section{References}

I. Hunink MG, Goldman L, Tosteson AN, Mittleman MA, Goldman PA, Williams $L W$, et al.: The recent decline in mortality from coronary heart disease, 1980-1990. The effect of secular trends in risk factors and treatment. JAMA 1997, 277:535-42.

2. Statistics Canada. Causes of Death 2003 [http://www.stat can.ca/english/freepub/84-208-XIE/2005002/tables.htm\#9]. accessed July 20, 2008

3. The Growing Burden of Heart Disease and Stroke in Canada 2003. Heart and Stroke Foundation of Canada [http://
[hen www.cvdinfobase.ca/crdbook/CVD En03.pdf]. accessed July 20, 2008

4. Economic Burden of Illness in Canada, Policy Research Division, Strategic Policy Directorate, Population and Public Health Branch, Health Canada [http://www.phac-aspc.gc.cal publicat/ebic-femc98/index-eng.php]. accessed October 20, 2000 
5. Scandinavian Simvastatin Survival Study Group: Randomised trial of cholesterol lowering in $\mathbf{4 4 4 4}$ patients with coronary heart disease: the Scandinavian Simvastatin Survival Study (4S). Lancet 1994, 344:1383-89.

6. Sacks FM, Pfeffer MA, Moye LA, Rouleau JL, Rutherford JD, Cole TG, et al.: The effect of pravastatin on coronary events after myocardial infarction in patients with average cholesterol levels. N Engl J Med 1996, 335:1001-9.

7. The Long-Term Intervention with Pravastatin in Ischaemic Disease (LIPID) Study Group: Prevention of cardiovascular events and death with pravastatin in patients with coronary heart disease and a broad range of initial cholesterol levels. $N$ Engl J Med 1998, 339: 1349-57.

8. MRC/BHF Heart Protection Study of cholesterol lowering with simvastatin in 20,536 high-risk individuals: a randomised placebo-controlled trial. Lancet 2002, 360:7-22.

9. Schwartz GG, Olsson AG, Ezekowitzz MD, et al.: Effects of atorvastatin on early recurrent ischemic events in acute coronary syndromes: the MIRACL study: a randomized controlled trial. JAMA 200I, 285:I7II-8.

10. Shepherd J, Blauw GJ, Murphy MB, Bollen EL, Buckley BM, Cobbe SM, on behalf of the PROSPER study group, et al.: Lancet 2002, 360:1623-30.

II. Cannon CP, Braunwald E, McCab CH, Rader DJ, Rouleau JL, Belder $\mathrm{R}$, for the pravastatin or atorvastatin evaluation and infection therapythrombolysis in myocardial infarction 22 investigators, et al.: Intensive versus moderate lipid lowering with statins after acute coronary syndromes. N Engl J Med 2004, 350: |495-504.

12. de Lomos JA, Blazing MA, Wiviott SD, Lewis EF, Fox KA, White HD, for the $A$ to $Z$ Investigators: Early intensive vs a delayed conservative simvastatin strategy in patients with acute coronary syndromes. Phase $\mathbf{Z}$ of the $\mathbf{A}$ to $\mathbf{Z}$ trial. JAMA 2004 292:1307-16.

13. LaRosa JC: Justifying lipid-lowering therapy in persons $\exists \mathbf{6 5}$ years of age. Am Journ Cardiol 2002, 90:1330-32.

14. Dombrook-Lavender KA, Roth MT, Pieper JA: Secondary prevention of coronary heart disease in the elderly. Ann Pharmacol 2003, 37: 1867-76.

15. Grundy SM: Statin therapy in older persons: Pertinent issues. Arch Intern Med 2002, 162:1329-31.

16. Kagansky N, Levy S, Berner Y, Rimon E, Knobler H: Cholesterol lowering in the older population: time for reassessment? $Q$ Med 200I, 94:457-63.

17. Teo KK, Burton JR: Who should receive HMG CoA reductase inhibitors? Drugs 2002, 62:1707-15.

18. Jackevicius CA, Anderson GM, Leiter L, Tu JV: Use of statins in patients after myocardial infarction. Does evidence change practice. Arch Intern Med 200I, 16I:183-8.

19. Levy AR, O'Brien BJ, McCullen E, May FW, Demers C, Marshall D, et al: Rapid increase in statins newly dispensed to Ontario seniors between 1994 and 2000. Can J Cardiol 2003, 19:665-9.

20. Cooke C, Nissan L, Sketris I, Tett S: Quantifying the Use of the Statin Antilipemic Drugs: Comparisons and Contrasts Between Nova Scotia, Canada, and Queensland, Australia. Clin Ther 2005, 27:497-508.

21. Rothwell P: External validity of randomised controlled trials 'To whom do the results of this trial apply?'. Lancet 2005, 365:82-93.

22. Wieringa NF, Vos R, Werf GT van der, Veen WJ van der, de Graeff PA: Co-morbidity of 'clinical trial' versus 'real-world' patients using cardiovascular drugs. Pharmacoepidemiol Drug Saf 2000, 9:569-79.

23. Martin K, Begaud B, Latry P, Miremont-Salame G, Fourrier A, Moore $\mathrm{N}$ : Differences between clinical trials and postmarketing use. BrJ Clin Pharmacol 2004, 57:86-92

24. Cox JL, Johnstone D, Nemis-White J, Montague T, for the ICONS Investigators, Optimizing Healthcare at the Population Level: Results of the Improving Cardiovascular Outcomes in Nova Scotia Partnership, Healthcare Quarterly. 2008, I I (2):28-4I

25. Cox JL: Optimizing disease management at a health care system level: the rationale and methods of the improving cardiovascular outcomes in Nova Scotia (ICONS) study. Can J Cardiol 1999, I 5(7):787-796.

26. Population Health Research Unit (PHRU) [http:// www.phru.dal.ca/]. accessed July 20, 2008
27. Health Canada. Drug Product Database [http://www.hcsc.gc.ca/dhp-mps/prodpharma/databasdon/index-eng.php]. accessed October 20, 2009

28. World Health Organization Collaborating Centre for Drug Statistics Methodology: ATC Index with DDDs, 2002. Oslo, Norway: World Health Organization; 2002.

29. Psaty BM, Koepsell TD, Lin D, Weiss NS, Siscovick DS, Rosendaal FR, et al.: Assessment and control for confounding by indication in observational studies. J Am Geriatr Soc 1999, 47:749-54

30. Rockwood K, Kirkland S, Hogan DB, MacKnight C, Merry H, Verreault $R$, et al.: Use of lipid-lowering agents, indication bias, and the risk of dementia in community-dwelling elderly people. Arch Neurol 2002, 59:223-7.

3I. Signorello LB, McLaughlin JK, Lipworth L, Friis S, Sorensen HT, Blot W]: Confounding by indication in epidemiologic studies of commonly used analgesics. Am J Ther 2002, 9: 199-205.

32. Concato J, Horwitz RI: Beyond randomized versus observational studies (Commentary). Lancet 2004, 363:1660-6I.

33. Schneeweiss S, Seeger JD, Maclure M, Wang PS, Avorn J, Glynn RJ: Performance of comorbidity scores to control for confounding in epidemiologic studies using claims data. Am J Epidemiol 200I, I 54:854-64.

34. Schneeweiss S, Wang PS, Avorn J, Glynn RJ: Improved comorbidity adjustment for predicting mortality in Medicare populations. Health Serv Res 2003, 38: I I03-20.

35. Schneeweiss S, Wang PS, Avorn J, Maclure M, Levin R, Glynn RJ: Consistency of performance ranking of comorbidity adjustment scores in Canadian and U.S. utilization data. J Gen Intern Med 2004, 19:444-50.

36. Schneeweiss S, Maclure M: Use of comorbity scores for control of confounding in studies using administrative databases. Int J Epidemiol 2000, 29:89I-8.

37. Glynn RJ, Knight EL, Levin R, Avorn J: Paradoxical relations of drug treatment with mortality in older persons. Epidemiology 2001, 1 2:682-89.

38. Ko DT, Mamdani M, Alter DA: Lipid-lowering therapy with statins in high-risk elderly patients: the treatment paradox. JAMA 2004, 29I: I864-70.

39. Yang CC, Jick SS, Testa MA: Who receives lipid-lowering drugs: the effects of comorbidities and patient characteristics on treatment initiation. Br J Clin Pharmacol 2003, 55:288-98.

40. D'Agostino RB: Propensity score methods for bias reduction in the comparison of a treatment to a non-randomized control group. Statist Med 1998, 17:2265-8I.

4l. Rubin DB: Estimating causal effects from large data sets using propensity scores. Ann Intern Med 1997, I 27:757-63.

42. Rosenbaum PR, Rubin DB: The central role of the propensity score in observational studies for causal effects. Biometrika 1983, 70:4I-55

43. Joffe MM, Rosenbaum PR: Invited commentary: propensity scores. Am J Epidemiol 1999, 150:327-33.

44. Ohman EM, Granger CB, Harrington RA, Lee KL: Risk stratification and therapeutic decision making in acute coronary syndromes. JAMA 2000, 284:876-878

45. SAS/ETS Version 8.2 Cary, North Carolina: SAS Institute Inc; 2001.

46. National Cholesterol Education Program (NCEP) Expert Panel on Detection, Evaluation, and Treatment of High Blood Cholesterol in Adults (Adult treatment Panel III): Third report of the National Cholesterol Education Program (NCEP) Expert Panel on Detection, Evaluation, and Treatment of High Blood Cholesterol in Adults (Adult treatment III final report). Circulation 2002, 106:3|43-2I.

47. Tonkin A, Barter P, Best J, Boyden A, Furler J, Hossack K, et al.: National Heart Foundation of Australia and the Cardiac Society of Australia and New Zealand: position statement on lipid management--2005. Heart Lung Circ 2005, 14(4):275-91.

48. Fonarow GC. French WJ, Parsons LS, Sun H, Malimgreen JA, for the National Registry of Myocardial Infarction 3 Participants: Use of lipid-lowering medications at discharge in patients with acute myocardial infarction. Data from the National Registry of Myocardial Infarction 3. Circulation 200I, 103:38-44.

49. Beck CA, Lauzon C, Eisenberg MJ, Huynh T, Dion D, Roux R, Racine N, Carignan S, Diodati JG, Charbonneau F, Levesque C, Pouliot JJ, Pilote LL: Discharge prescriptions following admission for acute myocardial infarction at tertiary care and community hospitals in Quebec. Can J Cardiol 200I, 17:33-40. 
50. Pilote L, Beck CA, Karp I, Alter D, Austin P, Cox J, Humphries K, Jackevicius C, Richard H, Tu JV, Canadian Cardiovascular Outcomes Research Team: Secondary prevention after acute myocardial infarction in four Canadian provinces, 1997-2000. Can J Cardiol 2004, 20(I):6I-7.

5I. Simpson E, Beck C, Richard H, Eisenberg MJ, Pilote L: Drug prescriptions after acute myocardial infarction: dosage, compliance, and persistence. Am Heart J 2003, I 45:438-44.

52. McAlister FA, Taylor L, Teo KK, Tsuyuki RT, Ackman ML, et al.: The treatment and prevention of coronary heart disease in Canada: do older patients receive efficacious therapies? The Clinical Quality Improvement Network (CQIN) Investigators. J Am Geriatr Soc 1999, 47:8। I-8.

53. Harrold LR, Lessard D, Yarzebski J, Gurwitz JH, Gore JM, Goldberg $\mathrm{RJ}$ : Ageand sex differences in the treatment of patients with initial acute myocardial infarction: a community-wide perspective. Cardiology 2003, 99:39-46.

54. Sgadari A, Incalzi RA, Onder G, Pedone C, Gambassi G: Lipid-lowering therapy in patients with coronary artery disease: sex or age bias? (Letter). Arch Intern Med 2000, I 60:2684-5.

55. Miller M, Byington R, Hunninghake D, Pitt B, Furberg CD: Sex bias and underutilization of lipid-lowering therapy in patients with coronary artery disease at academic medical centers in the United States and Canada. Prospective Randomized Evaluation of the Vascular Effects of Norvasc Trial (PREVENT) Investigators. Arch Intern Med 2000, I 60:343-7.

56. Alter DA, Naylor CD, Austin PC, Tu JV: Biology or bias: practice patterns and long-term outcomes for men and women with acute myocardial infarction. J Am Coll Cardiol 2002, 39:1909-I6.

57. Majeed A, Moser K, Maxwell R: Age, sex and practice variations in the use of statins in general practice in England and Wales. J Public Health Med 2000, 22:275-9.

58. Stocks NP, Ryan P, McElroy H, Allan J: Statin prescribing in Australia: socioeconomic and sex differences. A cross-sectional study. Med J Aust 2004, I80:229-3I.

59. DeWilde S, Carey IM, Bremner SA, Richards N, Hilton SR, Cook DG: Evolution of statin prescribing 1994-200 I: a case of agism but not of sexism? Heart 2003, 89:4I7-2I.

60. Williams D, Bennett K, Feely J: Evidence for an age and gender bias in the secondary prevention of ischaemic heart disease in primary care. Br J Clin Pharmacol 2003, 55:604-8.

61. Miettinen TA, Pyorala K, Olsson AG, Musliner TA, Cook TJ, Faergeman $\mathrm{O}$, et al.: Cholesterol-lowering therapy in women and elderly patients with myocardial infarction or angina pectoris: findings from the Scandinavian Simvastatin Survival Study (4S). Circulation 1997, 96:42 I I-8

62. Lewis SJ, Moye LA, Sacks FM, Johnstone DE, Timmis G, Mitchell J, et al.: Effect of pravastatin on cardiovascular events in older patients with myocardial infarction and cholesterol levels in the average range. Results of the Cholesterol and recurrent Events (CARE) trial. Ann Intern Med 1998, I 29:68I-89.

63. Hunt D, Young P, Simes J, for the LIPID investigators, et al.: Benefits of pravastatin on cardiovascular events and mortality in older patients with coronary heart disease are equal to or exceed those seen in younger patients: results from the LIPID trial. Ann Intern Med 200I, 134:931-40.

64. Acevedo M, Sprecher DL, Lauer MS, Francis G: Routine statin treatment after acute coronary syndromes? Am Heart J 2002, I 43:940-2.

65. Isles CG: Patients with acute coronary syndrome should start a statin while still in hospital [editorial]. Heart 2002, 88:5-6.

66. Fonarow CG, Ballantyne CM: In hospital initiation of lipid lowering therapy for patients with coronary heart disease: the time is now. Circulation 200I, I03:2768-70.

67. Olsson AG, Schwartz: Early initiation of treatment with statins in acute coronary syndromes. Ann Med 2002, 34:37-4I.

68. Spin JM, Vagelos RH: Early use of statins in acute coronary syndromes. Curr Atheroscler Rep 2003, 5:44-5I.

69. Paradiso-Hardy FL, Gordon WL, Jackevicius CA, Kertland HR, Pearson G], Pickering JL, Poirier L, Semchuk BM, Verret L: The importance of in-hospital statin therapy for patients with acute coronary syndromes. Pharmacotherapy 2003, 23:506-I3.

70. Eaton CB, Lapane KL, Murphy JB, Hume AL: Effect of statin (HMG Co-A-Reductase inhibitor) use on I-year mortality and hospitalization rates in older patients with cardiovascular dis- ease living in nursing homes. J Am Geriatr Society 2002 , 50: $1389-95$

7I. Roos NP, Mustard CA: Variation in health and health care use by socioeconomic status in Winnipeg, Canada: does the system work well? Yes and no. Millbank $Q$ 1997, 75:89-III.

72. Wilson DM, Truman CD: Evaluating institutionalization by comparing the use of health services before and after admission to a long-term-care facility. Eval Health Prof 2004, 27:219-36.

73. Wilt TJ, Bloomfield HE, MacDonald R, Nelson D, Rutzs I, Ho M, et al.: Effectiveness of Statin Therapy in Adults with Coronary Heart Disese. Arch Intern Med 2004, 164:1427-36.

74. Afilalo J, Duque G, Steele R, Jukema JW, de Craen AJM, Eisenberg M: Statins for Secondary Prevention in Elderly Patients: A Hierarchical Bayesian Meta- Analysis. JACC 2008, 5 I (I):37-45.

75. Allen-Maycock CA, Muhlestein JB, Horne BD, Carlquist JF, Bair TL, et al.: Statin therapy is associated with reduced mortality across all age groups of individuals with significant coronary disease, including very elderly patients. JACC 2002, 40: I777-85.

76. Aronow HD, Topol EJ, Roe MT, Houghtaling PL, Wolski KE, et al: Effect of lipid-lowering therapy on early mortality after acute coronary syndromes: an observational study. Lancet 2001, 357:1063-8.

77. Wei L, Ebrahim S, Bartlett C, Davey PG, Sullivan FM, MacDonald TM: Statin use in the secondary prevention of coronary heart disease in primary care: cohort study and comparison of inclusion and outcome with patients in randomised trials. $B M J$ 2005, 330:821.

78. Foody JM, Rathore SS, Galusha D, Masoudi FA, Havranek EP, Radford MJ, Krumholz HM: Hydroxymethylglutaryl-CoA reductase inhibitors in older persons with acute myocardial infarction: evidence for an age-statin interaction. J Am Geriatr Soc 2006 54:42l-30.

79. Dunlop S, Coyte PC, Mclsaac W: Socio-economic status and the utilisation of physicians' services: results from the Canadian National Population Health Survey. Soc Sci Med 2000, 5 I:I23-33.

80. Pilote L, Beck C, Richard H, Eisenberg MJ: The effects of cost-sharing on essential drug prescriptions, utilization of medical care and outcomes after acute myocardial infarction in elderly patients. CMAJ 2002, 167:246-52.

8I. Pilote L, Joseph L, Belisle P, Penrod J: Universal health insurance coverage does not eliminate inequities in access to cardiac procedures after acute myocardial infarction. Am Heart J 2003, 146:1030-7.

\section{Pre-publication history}

The pre-publication history for this paper can be accessed here:

\section{http://www.biomedcentral.com/1472-6963/9/198/pre} pub

Publish with Bio Med Central and every scientist can read your work free of charge

"BioMed Central will be the most significant development for disseminating the results of biomedical research in our lifetime. "

Sir Paul Nurse, Cancer Research UK

Your research papers will be:

- available free of charge to the entire biomedical community

- peer reviewed and published immediately upon acceptance

- cited in PubMed and archived on PubMed Central

- yours - you keep the copyright 